\title{
Adsorbate-Induced Structural Evolution of Pd Catalyst for the Selective Hydrogenation of Acetylene
}

Yanan Liu ${ }^{a, b}$, Fengzhi Fu ${ }^{a}$, Alan McCue ${ }^{c, *}$, Wilm Jones ${ }^{d}$, Deming Rao ${ }^{e}$, Junting

$$
\text { Feng }^{a, b, *} \text { Yufei He } e^{a, b} \text {, Dianqing } \mathrm{Li}^{a, b, *}
$$

a State Key Laboratory of Chemical Engineering, Beijing University of Chemical Technology, Beijing 100029, China

${ }^{\mathrm{b}}$ Beijing Engineering Center for Hierarchical Catalysts, Beijing University of Chemical Technology, Beijing, 100029, China

${ }^{c}$ Department of Chemistry, University of Aberdeen, Aberdeen AB24 3UE, UK

${ }^{\mathrm{d}}$ Department of Chemistry, University College London, 20 Gower Street, London WC1E 6BT, UK

e Institute of Science and technology strategy, Jiangxi academy of science, Jiangxi 330096, China

\begin{abstract}
This work describes the transformation of $\mathrm{Pd}$ species under reaction condition to control the reactivity of heterogeneous catalysts, in which the real active sites for hydrogenation differ from simple Pd sites on a carbon nanofiber. Specifically, in the presence of $\mathrm{C}_{2} \mathrm{H}_{2} / \mathrm{C}_{2} \mathrm{H}_{4} / \mathrm{H}_{2}$ reaction mixtures, a permeable amorphous hydrocarbon overlayer is formed with simultaneous insertion of carbon atoms into $\mathrm{Pd}$ lattice that drives the formation of low coordinated Pd-carbide, thus providing more reactive Pd- $\mathrm{C}_{\text {sub }} @ \mathrm{C}_{\text {layer }}$ sites $\left(\mathrm{C}_{\text {sub: }}\right.$ subsurface carbon; $\mathrm{C}_{\text {layer: }}$ carbon layer on the surface). The combination of these surface and subsurface effects hinders Pd-hydride, weakens ethylene adsorption confirmed by density functional theory (DFT) calculation, and thus improve catalytic behaviour for selective hydrogenation of acetylene (93\% ethylene selectivity @100\% conversion) with long-term stability. In the absence of hydrogen, a denser more crystalline overlayer is formed with severely restricted permeability, resulting in significantly lower activity. Moreover, by X-ray absorption
\end{abstract}


spectroscopy (XAS) and in-situ X-ray diffraction (XRD), it is demonstrated that different active sites dominate this catalytic reaction depending on choice of adsorbate and exposure temperature. This work represents an alternative and arguably simpler manner to design more reactive catalytic sites with the characteristics of long-term stability and facile preparation which would enable promising industrial application.

Keywords: Adsorbate induced, structural evolution, Pd carbide, permeable carbon layer, selective acetylene hydrogenation

\section{Introduction}

The selective hydrogenation of acetylene is a key purification step for producing the polymer grade ethylene required for making polyethylene. For many decades, this has been achieved over palladium containing catalysts since Pd is highly active ${ }^{1,2}$. When both acetylene and ethylene are present in a feed stream, acetylene is preferentially adsorbed as its enthalpy of adsorption is greater than that of ethylene ${ }^{3,4}$. However, to achieve the level of purification necessary $(<5$ ppm acetylene) high conversion must be reached which means ethylene has unimpeded access to the surface, thus leading to ethane formation ${ }^{5}$. Meanwhile, Pd hydride phases can form ( $\alpha-\mathrm{PdH}$ and $\beta-\mathrm{PdH})$ in the presence of hydrogen resulting in the formation of reactive subsurface hydrogen which enhances ethylene hydrogenation upon migration back to the surface ${ }^{6,7}$. A broad range of alternative catalyst formulations for improving selectivity to ethylene by inhibiting $\beta-\mathrm{PdH}$ phase have been reported in recent years including alternative monometallic ${ }^{8,9}$, bimetallics ${ }^{10,11}$, metal oxides ${ }^{12}$, sulfides ${ }^{13,14}$ and phosphides ${ }^{15,16}$, although in many cases application is limited. For example, operation at shorter time on stream, higher temperature and/or lower pressure than current reactors permit mean they are not necessarily 'drop-in' replacements. In addition, sample preparation can be complex and ill-suited to scale-up. As such, palladium-based catalysts are still the industrial norm.

Over the years, less has been known about how active metal species can be transformed under reaction condition (i,e., the real active sites may differ from 
expectation or design) or whether this aspect can be exploited to control catalyst reactivity. As structural characterisation techniques have become more advanced, so has our understanding of the phenomena which occur with structural changes of active metal depending on environment and/or temperature. A complex array of surface species may also exist under reaction condition, some of which may lead to carbonaceous deposits, whereas others may be spectator species ${ }^{17}$. These deposits have been considered as an adlayer which changes the active site geometry with the discontinuous $\mathrm{Pd}$ sites assumed to favour selective hydrogenation and larger ensembles favouring unselective hydrogenation (note: this explanation is equivalent to the geometric effect created by industrial PdAg catalysts which offer enhanced selectivity). This interpretation has become less popular in recent years as our understanding of how a Pd-carbide phase can form under operational conditions has been improved. Numerous studies (both experimental and theoretical in nature) ${ }^{18,19}$ have shown that this metastable Pd-carbide phase may influence selectivity which has led to a more contemporary belief that the interplay between Pd-hydride and carbide phases holds the key to controlling product distribution. Meanwhile, the spectator surface carbon species can be also employed to decorate/tune reaction behaviour via modifying electronic and geometric structures ${ }^{20}$. However, the carbon overlayer often consists of thick multi-layer graphitic carbon species which may cover the active metal sites, block the access of reactants, rendering supported metals inactive due to the impermeability ${ }^{21,22}$, and thus need to remove ${ }^{23}$. However, if it is possible to create a permeable carbon overlayer then this would be far more appealing since reactivity should be preserved. For instance, Kim et al. ${ }^{24}$ fabricated Pt nanoparticles with a 1-2 layer-thick graphene, and found that the porous layer permitted the reactant accessibility, which resulted in good electrochemical activities and stability. Furthermore, Pérez-Ramírez and coworkers ${ }^{25}$ transformed high-density amorphous carbon into $\mathrm{Ru}$ coated graphene shells. The formation of permeable graphene layer not only contributed to preferable activity and selectivity, but also improved the stability for acetylene hydrochlorination. In pursuit of this goal, we have subsequently 
explored adsorbate induced restructuring of Pd particles and show how this can yield a catalyst which is more selective, even at high acetylene conversion.

Herein, carbon nanofiber supported Pd nanoparticles are pre-treated in acetylene/ethylene/hydrogen mixtures via programmed temperature, which induces the structural changes involving simultaneous formation of $\mathrm{Pd}$-carbide $\left(\mathrm{C}_{\text {sub }}\right)$ and a permeable carbon overlayer $\left(\mathrm{C}_{\text {layer }}\right)$ which can alter product selectivity in favour of ethylene. In other words, evidence is presented that suggests both the classic and contemporary interpretation regarding $\mathrm{Pd}$ catalysts are simultaneously valid. Moreover, by in situ XRD and XAS, it is demonstrated that, different active sites (Pd-C $\mathrm{C}_{\text {sub }} @ \mathrm{C}_{\text {layer }}$ versus Pd) dominate this catalytic reaction at different adsorbates and temperatures. Through combined experimental and theoretical methods, it is shown that $\mathrm{C}_{2} \mathrm{H}_{4}$ desorption and $\mathrm{H}_{2}$ activation synergistically regulate the reactivity of active Pd- $\mathrm{C}_{\text {sub }} @ \mathrm{C}_{\text {layer }}$ sites for the selective hydrogenation of acetylene. The adsorbate induced structural transformation of Pd species and the insight on real active sites in the reaction process shed further light on industrial catalysis and offer a fresh route for enhancing selectivity if these changes are well understood.

\section{Results}

Carbon nanofiber (PR24-HHT, Applied Sciences Inc.; CNF) supported Pd nanoparticles were fabricated by incipient wetness impregnation as reported previously with 1 wt. $\%$ Pd loading. ${ }^{26}$ The sample was subjected to reduce at $523 \mathrm{~K}$ in $10 \% \mathrm{H}_{2} / \mathrm{N}_{2}$ for $1 \mathrm{~h}$ prior to use and is denoted as $\mathrm{Pd} / \mathrm{CNF}-\mathrm{H}$ with an average particle size of $1.6 \mathrm{~nm}$. A portion of this fresh Pd/CNF-H sample was used/treated with a flow of $0.6 \% \mathrm{C}_{2} \mathrm{H}_{2} / 5.4 \% \mathrm{C}_{2} \mathrm{H}_{4} / 1.2 \%$ hydrogen/balance $\mathrm{N}_{2}$ at a space velocity of $240,000 \mathrm{~h}^{-1}$ in the temperature range $323-523 \mathrm{~K}$ (25 $\mathrm{K}$ increments, $5 \mathrm{~h}$ time on stream at each temperature). Following the entire sequence this sample was denoted as $\mathrm{Pd} @ \mathrm{C} / \mathrm{CNF}-\mathrm{TCH}$. An additional portion was treated with $\mathrm{C}_{2} \mathrm{H}_{2} / \mathrm{C}_{2} \mathrm{H}_{4}$ but in the absence of $\mathrm{H}_{2}$, denoted as $\mathrm{Pd} @ \mathrm{C} / \mathrm{CNF}-\mathrm{TC}$. Note that the coding 'Pd@C' implies carbon is incorporated as part of the Pd particle (see later). 


\section{Effect of in situ pretreatment on catalytic behaviour}

Freshly reduced $1 \mathrm{wt} \% \mathrm{Pd} / \mathrm{CNF}-\mathrm{H}$ catalyst prepared by impregnation was tested in the selective hydrogenation of $\mathrm{H}_{2} / \mathrm{C}_{2} \mathrm{H}_{2} / \mathrm{C}_{2} \mathrm{H}_{4}$ mixture (2:1:9 ratio) as a function of temperature (Figure 1A). The reaction sequence begins at $323 \mathrm{~K}$ where acetylene conversion is already $100 \%$. Operation under complete conversion is deliberate so that selectivity can be clearly determined over a catalyst which has already been exposed to acetylene. In the temperature range of 323-373 K, this sample favours ethane and oligomer formation with negligible ethylene formation (note: a negative ethylene selectivity implies a portion of that present in the feed undergoes hydrogenation). High oligomer formation is generally indicative of high molecular weight hydrocarbon lay down (see later). Notably, a shift in product distribution towards ethylene is seen as temperature increases beyond $373 \mathrm{~K}$. At $523 \mathrm{~K}$, a maximum ethylene selectivity of just under $72 \%$ is observed. In keeping with the report by Mei et al. ${ }^{27}$, this is preliminarily ascribed to the decrease of adsorbed $\mathrm{H}_{2}$ quantity as temperature increases $\left[\mathrm{Q}_{\mathrm{m}} @ 398 \mathrm{~K}\right.$ and $=10.9 \mu \mathrm{mol} / \mathrm{g} v_{s} \mathrm{Q}_{\mathrm{m}} @ 523 \mathrm{~K}=$ 6.7 $\mu \mathrm{mol} / \mathrm{g}$; Figure 1B]. The sample was cooled down (now denoted as $\mathrm{Pd} @ \mathrm{C} / \mathrm{CNF}-\mathrm{TCH})$ and the reaction sequence repeated. This dataset is displayed as Figure 1C and a number of key points can be noted. Firstly, complete conversion is still apparent across the entire temperature range which means any change in product distribution is not influenced by conversion. Secondly, the same general trend for selectivity versus temperature is observed for both Pd/CNF-H and Pd@C/CNF-TCH. Thirdly, selectivity to ethylene is enhanced across the entire temperature range (Figure 1A vs 1C). Notably, after $423 \mathrm{~K}$ there is a marked shift from ethane to ethylene with oligomer selectivity largely unchanged. Specifically, at $523 \mathrm{~K}$ the ethylene selectivity over Pd@C/CNF-TCH improves significantly (ca. 20\%) relative to Pd/CNF-H with a maximum ethylene selectivity of $93 \%$ observed. Turnover frequency (TOF) is an important metric to estimate the intrinsic activity and needs to be evaluated at low conversion $(<15 \%)$ in the absence of mass or heat transfer (verified by a 
Koros-Nowak test - Figure S2) ${ }^{28}$. As shown in Table S1, a TOF of $0.063 \mathrm{~s}^{-1}$ is achieved for Pd@C/CNF-TCH, which is superior to those of some Pd-based materials (i.e. monometallic Pd samples, bimetallic $\mathrm{PdAg}, \mathrm{PdCu}$ ) and comparable to the state of the art materials such as fresh Pd nanoparticles $\left(0.06 \mathrm{~s}^{-1}\right), \mathrm{Pd}_{1} / \mathrm{ND} @ \mathrm{G}\left(0.064 \mathrm{~s}^{-1} @\right.$ $\left.80^{\circ} \mathrm{C}\right)$ and $\mathrm{PdAuAg}\left(0.063 \mathrm{~s}^{-1}\right.$ at $\left.40^{\circ} \mathrm{C}\right)$. Higher TOF values have been reported for some systems but at higher hydrogen to acetylene ratios (3-25 fold excess of $\mathrm{H}_{2}$ ) or lower space velocity - Pd/brass-fiber, $\mathrm{Pd} / \mathrm{Ni}(\mathrm{OH})_{2}, \mathrm{Pd}-\mathrm{In}, \mathrm{CuPd}_{0.08}, \mathrm{Pd}_{15} \mathrm{Co}_{85}-700$ catalysts $\left(0.08-0.8 \mathrm{~s}^{-1}\right)$ (References listed in Supporting information). The above results imply that treatment under reaction conditions induce an adsorbate and/or temperature mediated change of catalyst structure which is conducive for producing a more active and selective catalyst. The stability of Pd@C/CNF-TCH and Pd/CNF-H catalyst was further assessed at both complete (100\% in Figure 1D) and sub maximal conversion (ca. $90 \%$ in Figure S3) over a $50 \mathrm{~h}$ period. The activity and selectivity to ethylene of Pd@C/CNF-TCH fluctuate in a small range regardless of the conversion degree, indicating this catalyst is stable under the reaction process (Figure S3), whilst the Pd/CNF-H catalyst does not show deactivation at only low conversion of $90 \%$. It is interesting to note that the space velocity employed in this work is ca. 40 times higher than typically employed in industry. So, in terms of the amount of acetylene the catalyst sees, the $50 \mathrm{~h}$ test from this work is greater than 1 month operation in an industrial reactor ${ }^{1,3}$. Moreover, HRTEM analysis of the two used catalysts at sub maximal conversion was conducted to evaluate the stability of catalyst structure (Figure S4). As expected, there is no obvious change in the thickness of the carbon layer or the size of metal nanoparticles in Pd@C/CNF-TCH, but the carbon deposition was observed on the surface of $\mathrm{Pd} / \mathrm{CNF}-\mathrm{H}$, which is agreement with the result after the pretreatment under same conditions. In order to explore the effect of a different pretreatment, a further sample was pre-treated in $\mathrm{C}_{2} \mathrm{H}_{2} / \mathrm{C}_{2} \mathrm{H}_{4}$ for the same time/temperature program but in the absence of $\mathrm{H}_{2}$. The obtained catalyst (denoted as Pd@C/CNF-TC) displays significantly different catalytic performance (Figure S5-A). More specifically, acetylene conversion over Pd@C/CNF-TC fluctuates between 10 
and $15 \%$ across the temperature range $323-523 \mathrm{~K}$. Along with a marked (non-Arrhenius) change in activity, the catalyst appears selective to ethylene ( $c a$. $100 \%$ ), although this is simply attributable to decreased conversion. The disproportionate change in catalyst activity and selectivity cannot be rationalized simply. Instead is thought to be related to a more complex reaction environment including adsorbate and temperature induced structural transformation ${ }^{29}$.
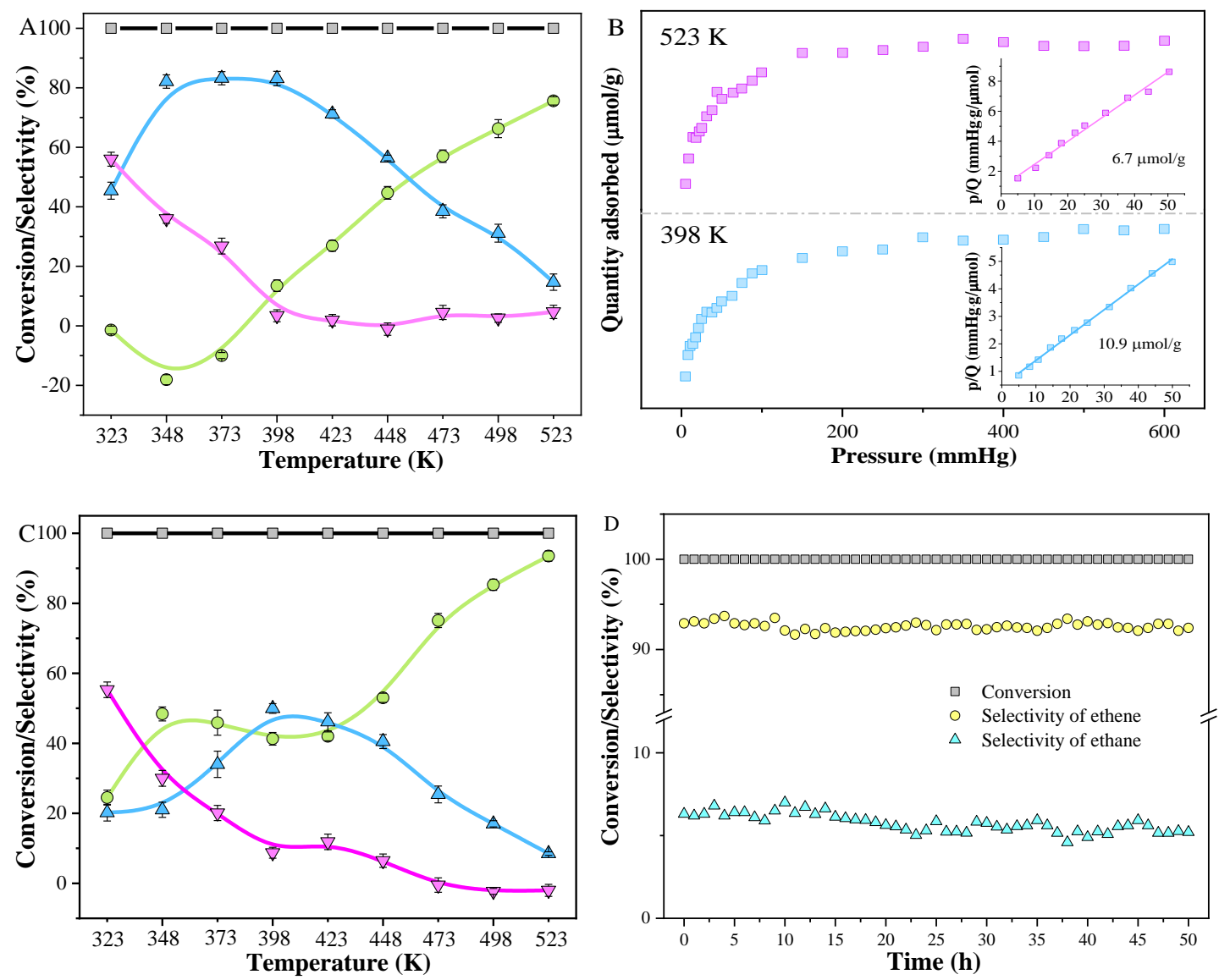

Figure 1. (A) Conversion (grey squares), selectivity of ethylene (green circles), ethane (cyan triangles) and oligomers (pink triangles) versus temperature over Pd/CNF-H; (B) Quantity of adsorbed $\mathrm{H}_{2}$ over Pd/CNF-H conducted from $0-600 \mathrm{mmHg}$, in which $\mathrm{p} / \mathrm{Q}$ (inlet) represents the ratio of pressure (p) to quantity adsorbed (Q); (C) Conversion and selectivity versus temperature (D) Long time on stream test at $523 \mathrm{~K}$ for $50 \mathrm{~h}$ period over Pd@C/CNF-TCH.

\section{Effect of in situ pretreatment on catalyst structure}


In order to rationalize the change in product distribution following different in-situ treatments, a series of characterisation methods were used. Firstly, the morphology of $\mathrm{Pd} / \mathrm{CNF}-\mathrm{H}$ was characterized by spherical aberration (Cs) corrected scanning transmission electron microscopy (STEM) revealing the hollow nature of CNF's and insight into the metal structure. As shown in Figure $2 \mathrm{~A}_{1}, \mathrm{Pd} / \mathrm{CNF}-\mathrm{H}$ material possesses monodisperse Pd nanoparticles with an average particle size of $1.6 \mathrm{~nm}$. In the highly magnified image (Figure $2 \mathrm{~A}_{2}$ ), lattice fringes of $0.225 \mathrm{~nm}$ are visible, corresponding to the (111) plane of metallic Pd. Notably, after treatment under reaction conditions $\left(\mathrm{C}_{2} \mathrm{H}_{2} / \mathrm{C}_{2} \mathrm{H}_{4} / \mathrm{H}_{2}\right)$, Pd@C/CNF-TCH sample shows no obvious change in particle size (inset Figure 2B), although it did contain some larger particles, and thus the effect of nanoparticle sizes on the catalytic performance especially the activity is not thought to be significant for these two catalysts. However, the metal particles appear to be covered by a disordered carbon layer with thickness of $c a .2 \mathrm{~nm}$ (Figure $2 \mathrm{~B}_{2}$ and $2 \mathrm{~B}_{3}$ ). Consequently, it appears, as a first approximation, that the adsorbate-mediated Pd@C/CNF-TCH catalyst possesses a core-shell type structure with metallic Pd as the core and disordered carbon as the shell. In this sample, Pd can be almost totally dissolved in aqueous $\mathrm{H}_{2} \mathrm{SO}_{4}$, suggesting that the layer is cracked or permeable (Figure S6A) ${ }^{30}$. In contrast, the sample treated in $\mathrm{C}_{2} \mathrm{H}_{2} / \mathrm{C}_{2} \mathrm{H}_{4}$ without $\mathrm{H}_{2}$ exhibits metallic Pd nanoparticles with a wider size distribution (4-50 nm) and the mean size is ca. $21 \mathrm{~nm}$. The agglomerated particle size likely leads to a significant reduction in the number of exposed active sites, which are further covered by the impermeable carbon layer with a layer thickness of $>20 \mathrm{~nm}$ (Figure $2 \mathrm{C}_{1-2}$ ) which results in poor activity. However, this is only a qualitative experiment, which is not fully convincing. In order to confirm the above conclusion, we performed chemisorption experiments with the reactants, taking $\mathrm{H}_{2}$ and $\mathrm{C}_{2} \mathrm{H}_{4}$ for example. By analyzing the results of $\mathrm{H}_{2}$ chemisorption (Table S2), the maximum adsorption capacity over Pd@C/CNF-TCH is estimated to be $10.4 \mu \mathrm{mol} / \mathrm{g}$, which is in good agreement with those of Pd/CNF-H but much higher than those of Pd@C/CNF-TC. Less adsorption implies either less accessible or less strongly adsorbed or both. The 
data illustrates that the amorphous carbon layer on the surface of Pd@C/CNF-TCH is permeable to the reactants, while the carbon species on the surface of Pd@C/CNF-TC blocks a large number of active sites. Moreover, to rule out the influence of layer thickness, we reduced the pretreatment time to control the thickness to $c a .2 \mathrm{~nm}$ (Figure $2 \mathrm{C}_{3}$ ) denoted as $\mathrm{Pd} @ \mathrm{C} / \mathrm{CNF}-\mathrm{TC}-1$, although the overlayer appears more structured and is not soluble in a strong acid (Figure S6B). This sample exhibits slightly improved catalytic activity relative to Pd@C/CNF-TC (Figure S5-A vs S5-B); however, conversion is still limited to less than $20 \%$. These results suggest the treatment in the presence of hydrogen leads to a more disordered and permeable carbon overlayer structure.

Figure 2D, 2E and S7 display the electron energy-loss spectra (EELS) from various spots of STEM images and gives qualitative evidence of the electronic state in the Pd catalyst and $\mathrm{C}$ matrix. In theory, the intensity of $\mathrm{Pd}-\mathrm{M}_{4,5}$ signals in EELS mainly reflects the density of the unoccupied electron states which are sensitive to the valence state of $\mathrm{Pd}^{31}$. For Pd/CNF-H (Figure 2D-2) a Pd:M4,5 signal is observed at $335 \mathrm{eV}$ (edges at 335-340 eV) which is consistent with Pd existing in the metallic state $^{32}$. There is no carbon peak present in Pd/CNF-H as shown in Figure 2E-1, indicating that no carbon species exist on the surface of fresh/pristine $\mathrm{Pd}$ after reduction. After sample treatment, both Pd@C/CNF-TCH, Pd@C/CNF-TC and Pd@C/CNF-TC-1 show more complex Pd-M4,5 signals which indicate a shift in valence state for Pd. This is likely associated with penetration of carbon into Pd bulk $(\text { see later })^{33}$. 

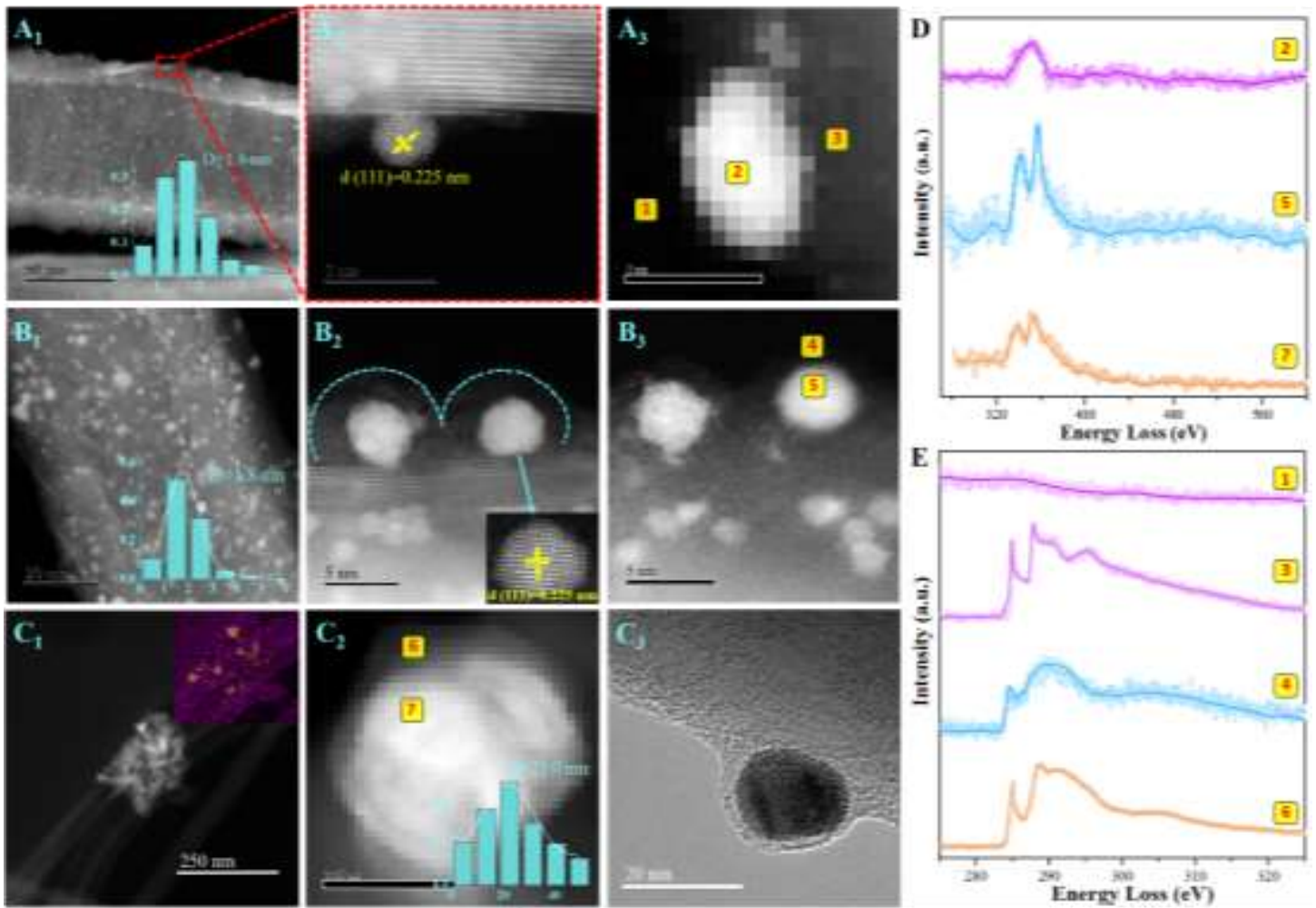

Figure 2. STEM images of (A) Pd/CNF-H (B) Pd@C/CNF-TCH $\left(\mathrm{C}_{1-2}\right) \mathrm{Pd} @ \mathrm{C} / \mathrm{CNF}-\mathrm{TC}\left(\mathrm{C}_{3}\right)$ Pd@C/CNF-TC-1 (D) EEL Pd spectra and (E) EEL C core-loss spectra. Numbering indicates where on the samples the EEL's data was acquired from.

X-ray photoelectron spectroscopy (XPS) measurements were also collected to gain insight into the surface and near-surface region of samples (Figure 3). For the $\mathrm{Pd} / \mathrm{CNH}-\mathrm{H}$ sample a $\mathrm{Pd} 3 \mathrm{~d}_{5 / 2}$ peak is apparent at $335.0 \mathrm{eV}$, attributed to $\mathrm{Pd}^{0}$. Interestingly, $\mathrm{Pd} @ \mathrm{C} / \mathrm{CNF}-\mathrm{TCH}$ sample has an asymmetric $\mathrm{Pd} 3 \mathrm{~d}_{5 / 2}$ peak which can be deconvoluted into two signals at 335.0 and $335.7 \mathrm{eV}$. This later peak is related to $\mathrm{Pd}$ existing in a partially carbide state ${ }^{6}$. The Pd spectrum collected for Pd@C/CNF-TC looks largely similar, although nosier and with a less intense signal. Given that the overlayer for this sample is far thicker it should be expected that the Pd signal is weaker if it is associated with the Pd-core. More notably, the peak intensity of carbide in this system decreases relative to that of Pd@C/CNF-TCH. Whilst the C 1s spectra for this sample is more complex (Figure 3B), deconvolution of the main C1s peak shows the peaks at $284.5,285.5$ and $286.5 \mathrm{eV}$, attributed to the CNF support ${ }^{34}$. The 
emergence of a shoulder at $283.4 \mathrm{eV}$ is close to that expected for a carbide phase (broadly consistent with EELS data) ${ }^{35}$. Moreover, the peaks at $288.5 \mathrm{eV}$ appear in the treated catalysts relative to $\mathrm{Pd} / \mathrm{CNF}-\mathrm{H}$ so likely originate from carbon laydown on surface. Comparison of the data from STEM with EELS and XPS analysis seems to indicate that carbon is incorporated into the catalyst in more than one manner. STEM reveals the presence of a surface layers with different thicknesses depending on pre-treatment environment whereas EELS and XPS results suggest that $\mathrm{C}$ is simultaneously incorporated into Pd nanoparticles to for a carbide phase.
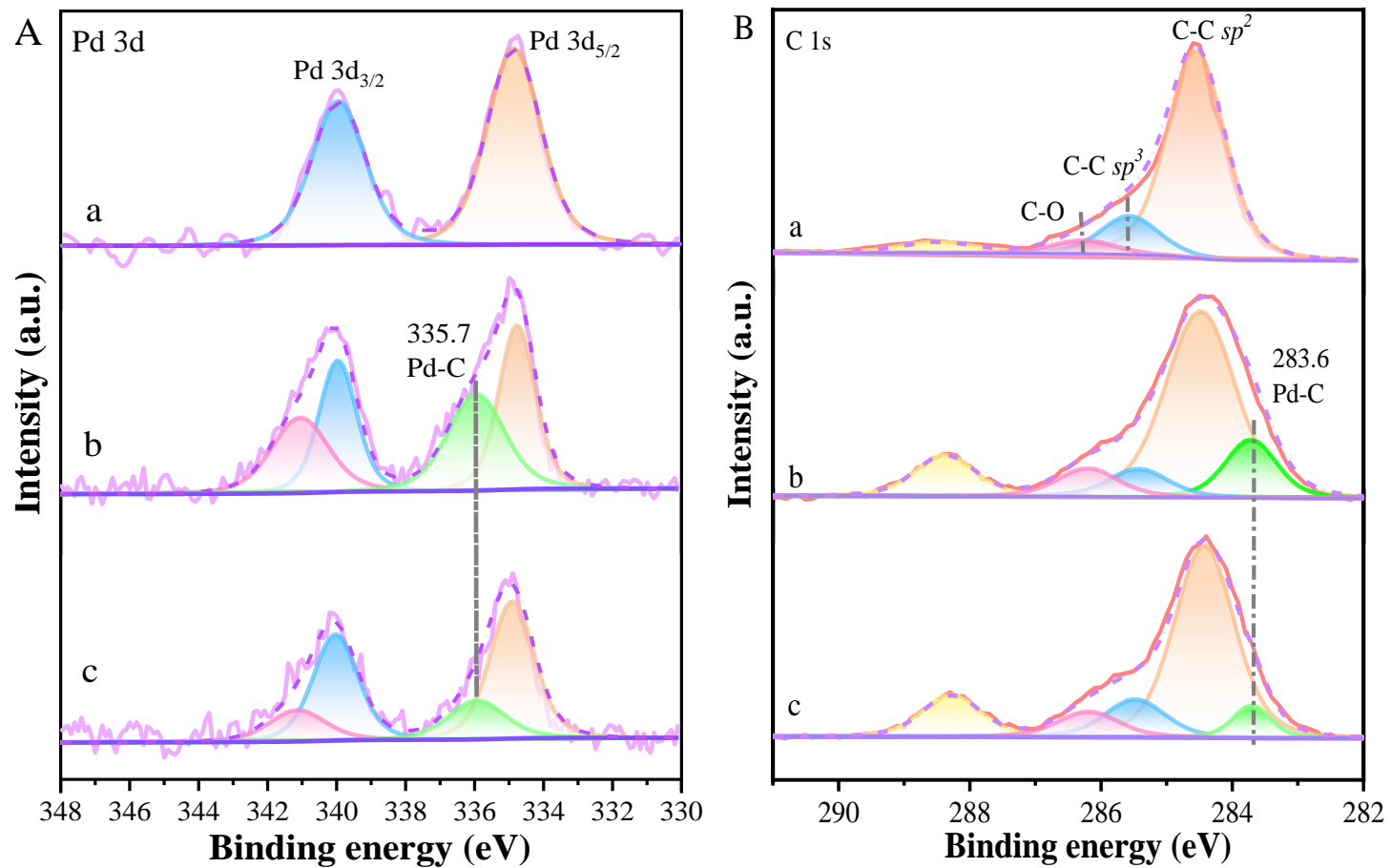

Figure 3. XP spectra of (A) Pd 3d and (B) C1s regions. Pd/CNF-H (a), Pd/CNF-TCH (b) and $\mathrm{Pd} / \mathrm{CNF}-\mathrm{TC}(\mathrm{c})$.

In-situ XRD was conducted to investigate carbide formation upon exposure to the reaction mixture. The profile of freshly reduced Pd/CNF-H (Figure 4A-a) exhibits the peak of monometallic $\mathrm{Pd}(111)$ at $40.1^{\circ}$. This sample was then heated stepwise to 373 , 423, 473 and $523 \mathrm{~K}$, in a $\mathrm{C}_{2} \mathrm{H}_{2} / \mathrm{C}_{2} \mathrm{H}_{4} / \mathrm{H}_{2} / \mathrm{N}_{2}$ flow to replicate the reaction sequence with XRD scans covering the Pd (111) peak $\left(2 \theta=36-42^{\circ}\right)$ collected along the way (Figure S1 indicates where in the reaction sequence XRD patterns $4 \mathrm{~A}-\mathrm{b}$ to e were 
collected). The peak of $\mathrm{Pd}(111)$ is seen to gradually shift towards lower angle until it reaches approximately $2 \theta$ of $39^{\circ}$, indicative of $\mathrm{Pd}$ carbide formation ${ }^{36}$ (i.e., Figure 4A-e). The incorporation of $\mathrm{C}$ atoms induces lattice expansion with the lattice parameter known to vary in proportion to the fraction of guest atoms $(\mathrm{x}=\mathrm{C} / \mathrm{Pd})$ according to the following equation: $\mathrm{a}=\mathrm{a}_{0}+0.69 \mathrm{x}^{37}$. Using this approach, an $\mathrm{x}=0.13$ value for Pd@C/CNF-TCH is obtained, corresponding to the carbon concentration of ca. $12 \%$. Notably, the shift of $\mathrm{Pd}$ (111) peak becomes more pronounced as temperature reaches and exceeds $423 \mathrm{~K}$ which is also the point where ethylene selectivity increases drastically (Figure 1A). This discovery demonstrates that, for Pd nanoparticles, distinct active sites may be present at different reaction temperatures which affect selectivity. In comparison, Pd (111) peak for Pd@C/CNF-TC (Figure 4A-a vs f) only displays a small shift to $39.8^{\circ}$ with $\mathrm{x}=0.04$, corresponding to a carbon content of ca. $4 \%$, confirming less Pd-carbide formation which agrees with XPS analysis.
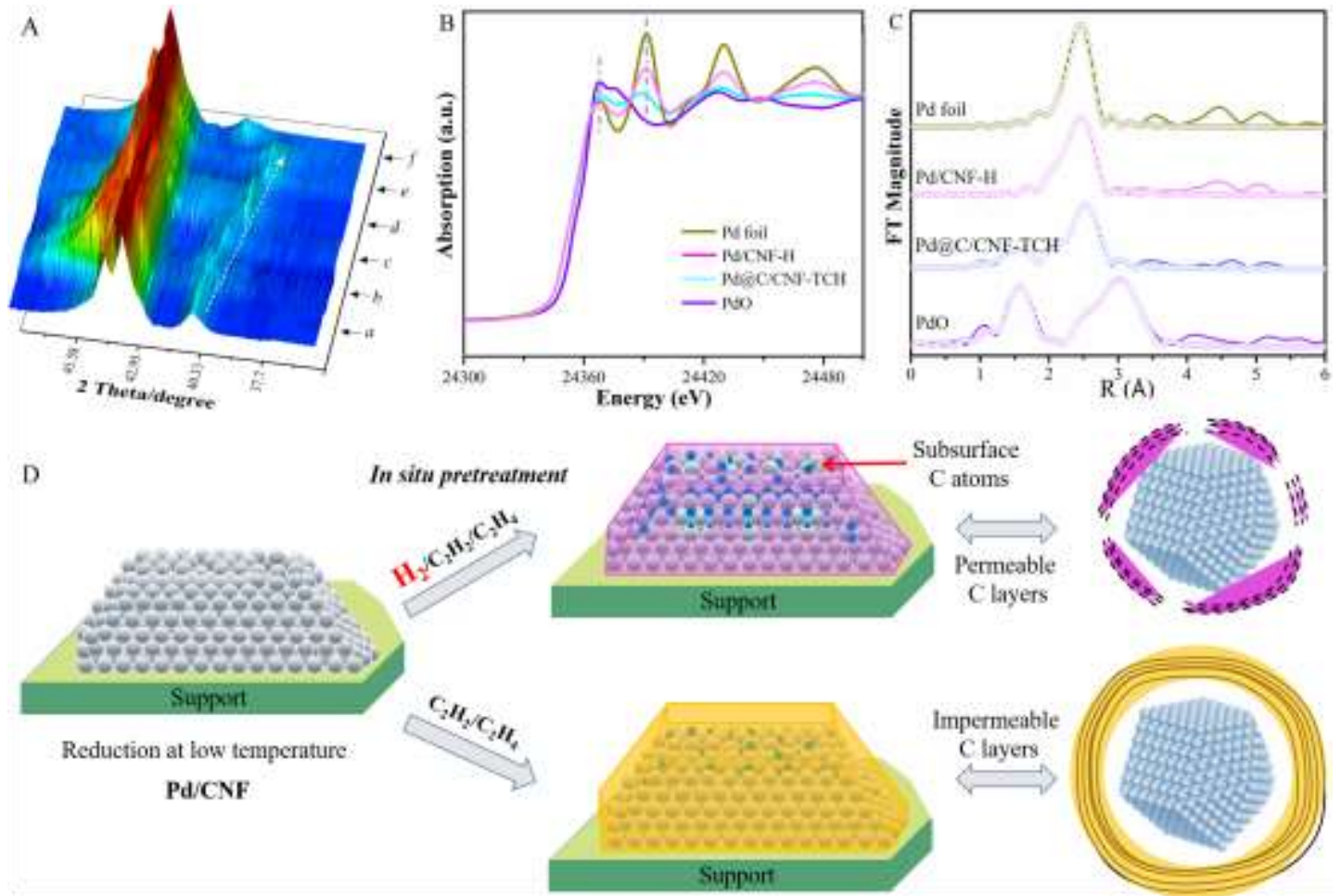

Subsurface
C atoms.
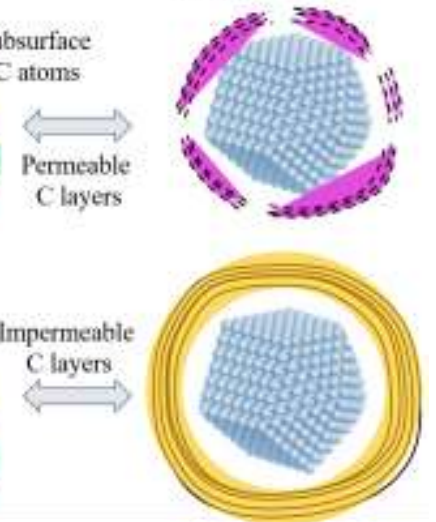

Figure 4. (A) In situ XRD patterns as $\mathrm{Pd} / \mathrm{CNF}-\mathrm{H}$ is converted into $\mathrm{Pd} @ \mathrm{C} / \mathrm{CNF}-\mathrm{TCH}$ and Pd@C/CNF-TC. a) Pd/CNF-H, treated in a $\mathrm{C}_{2} \mathrm{H}_{2} / \mathrm{C}_{2} \mathrm{H}_{4} / \mathrm{H}_{2} / \mathrm{N}_{2}$ at b) $373 \mathrm{~K}$, c) $423 \mathrm{~K}$, d) $473 \mathrm{~K}$, e) $523 \mathrm{~K}$ and $\mathrm{f}$ ) treated in a $\mathrm{C}_{2} \mathrm{H}_{2} / \mathrm{C}_{2} \mathrm{H}_{4} / \mathrm{N}_{2}$ at $523 \mathrm{~K}$ (B) XANES and (C) EXAFS of Pd/CNF-H, 
Pd@C/CNF-TCH along with Pd foil and PdO as reference. (D) Model of adsorbate induced structural changes with and without $\mathrm{H}_{2}$ presence.

Figure 4B shows the typical Pd K-edge X-ray absorption near edge structure (XANES) of palladium NPs observed after exposure of the sample to different pre-treatments. The intensity of treated samples sits between those for Pd foil and $\mathrm{PdO}$, clearly showing the unique electronic structure of $\mathrm{Pd}^{\delta+}(0<\delta<2)^{38}$. This observation also agrees well with the aforementioned XPS results. The XANES spectrum of $\mathrm{Pd} @ \mathrm{C} / \mathrm{CNF}-\mathrm{TCH}$ shows a significant broadening and increased intensity of the whiteline. Additionally, the position of the ls $\sim 4 \mathrm{f}$ resonance is shifted downward (by $2.2 \mathrm{eV}$ ) relative to that of Pd metal which is a simple result of lattice expansion due to the formation of a Pd-carbide phase ${ }^{39}$. Figure S8 and Figure 4C present the $\mathrm{k}^{3}$-weighted $\mathrm{Pd}$ K-edge X-ray absorption fine structure (EXAFS) oscillations and the corresponding Fourier transforms, respectively. The data fit describes the experimental data well up to ca.12 $\AA^{-1}$ for the $\chi^{3}(\mathrm{k})$ data. The Fourier transform spectra show two characteristic peaks in the range of 1.0-4.0 $\AA$. The peak at 1.6 $\AA$ is associated with Pd bonded to low $\mathrm{Z}$ elements ( $\mathrm{C}$ or $\mathrm{O}$ ) and the one at ca. 2.5 $\AA$ reflects Pd-Pd bonding in the first coordination shell ${ }^{40,41}$. The peak intensity is proportional to the coordination number and related to the degree of order/disorder of the corresponding coordination shells. This effect can be described by the Debye-Waller factor, which describes the mean square displacement of the inter-atomic distance between the absorbing atom and the backscattering atom due to vibration and static disorder (slightly different chemical environment). As shown in the fitting results (Figure 4, S9 and Table S3), Pd/CNF-H has a fitted Pd-Pd distance of $2.74 \AA$ with the coordination number $(\mathrm{CN})$ of 10.5 closest to that of Pd metal $(2.75$ $\AA$, 12) and a relatively small contribution from Pd-C or Pd-O. Interestingly, though not surprising, Pd@C/CNF-TCH sample has a far stronger Pd-C contribution with CN of 2.3 ( $\mathrm{Pd}-\mathrm{C}$ is assumed instead of Pd-O based on XRD studies) and the Pd-Pd bond distance deviates considerably from Pd metal $(2.80 \AA)$ with a low $\mathrm{CN}$ of 7.0. This 
EXAFS result of $\mathrm{Pd} @ \mathrm{C} / \mathrm{CNF}-\mathrm{TCH}$ catalyst reported in this work indicates the appearance of lattice expansion (around 1.8\%) under the treatment of $\mathrm{C}_{2} \mathrm{H}_{2} / \mathrm{C}_{2} \mathrm{H}_{4} / \mathrm{H}_{2}$, corresponding to a carbon concentration of ca. $12 \%$, which is generally consistent with reported parameters through XAS for Pd-C phase catalyst. This phenomenon further confirms that $\mathrm{C}$ atoms diffuse into the lattice of $\mathrm{Pd}$ nanoparticles rather than merely existing on the surface. More importantly, the Pd@C/CNF-TCH treated at 373 $\mathrm{K}$ has a fitted $\mathrm{Pd}-\mathrm{Pd}$ of $\mathrm{CN}=9.8$ closest to that of the $\mathrm{Pd}$ metal $(\mathrm{CN}=12)$, confirming temperature plays a critical role in controlling nanoparticle structure. This EXAFS data agrees with the observation in XANES (stronger interaction corresponds to a more intense whiteline). Based on combined STEM, EELS, XRD and XAS measurements a model of the adsorbate induced structural change is shown in Figure 4D. In the presence of a $\mathrm{C}_{2} \mathrm{H}_{2} / \mathrm{C}_{2} \mathrm{H}_{4} / \mathrm{H}_{2}$ mixture, the $\mathrm{Pd}$ nanoparticles becomes covered in a disordered but permeable carbon layer. As temperature is increased, carbon penetration into the bulk is more facile which leads to the formation of a Pd-carbide phase. These combined effects convert Pd sites into more selective low-coordinated Pd-C $\mathrm{C}_{\text {sub }} @ \mathrm{C}_{\text {layer }}$ sites. In the absence of hydrogen, the hydrocarbons form a more ordered and largely impermeable layer which decreases catalytic activity significantly and presumably hinders carbide formation.

\section{Insight into the change of catalyst structure affecting $\mathrm{C} 2$ hydrogenation}

To give a deeper insight into the correlation between structure and preferable catalytic activity, the adsorption and activation energies of hydrogen are calculated with respect to the gaseous energy of $1 / 2 \mathrm{H}_{2}$ considering the adsorption/activation of hydrogen is vital for the rate-determining step $^{42}$. Figure $5 \mathrm{~A}$ presents the adsorption and activation energies of hydrogen over the unmodified Pd (111) and Pd (111)-C surfaces calculated by density functional theory. The barrier for $\mathrm{H}_{2}$ dissociation is only $0.24 \mathrm{eV}$ on the Pd-C surfaces with an adsorption energy of $-0.48 \mathrm{eV}$, whereas the clean Pd catalyst has $\mathrm{H}_{2}$ dissociation and adsorption energies of $0.19 \mathrm{eV}$ and $-0.57 \mathrm{eV}$, respectively. This clearly indicates that the $\mathrm{Pd} @ \mathrm{C} / \mathrm{CNF}-\mathrm{TCH}$ catalyst provides 
weaker but similar active $\mathrm{H}$ species for acetylene hydrogenation relative to $\mathrm{Pd}$ sample. Why does the low-coordinated $\mathrm{Pd}-\mathrm{C}_{\text {sub }} @ \mathrm{C}_{\text {layer }}$ sites exhibit superior selectivity to ethylene? To resolve this issue, TPR experiment was first performed and Figure 5B shows that $\mathrm{Pd} / \mathrm{CNF}-\mathrm{H}$ sample releases hydrogen at $343 \mathrm{~K}$ which is consistent with the formation and subsequent decomposition of $\beta-\mathrm{PdH}_{\mathrm{x}}$ phase ${ }^{43}$. However, no such feature is apparent for the Pd@C/CNF-TCH sample, indicating that the subsurface carbon species hinder the formation of a hydride phase. These results indicate that the interplay between Pd-carbide and hydride phases plays a role in controlling ethylene selectivity.
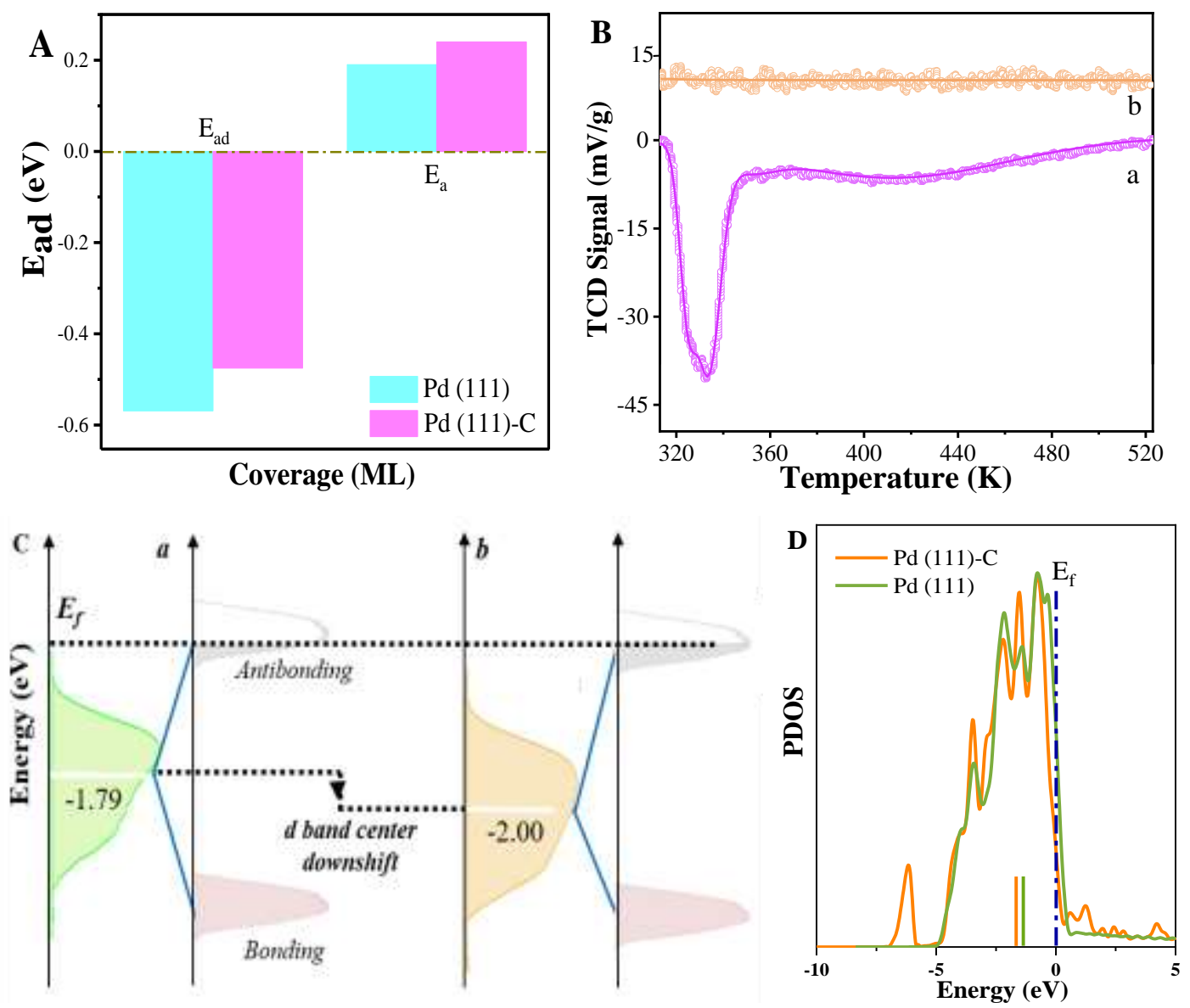

Figure 5. (A) Adsorption energy $\left(E_{a d}\right)$ and activation energy $\left(E_{a}\right)$ of hydrogen at the surface of $P d$ (111) and C-modified Pd (111) at the fixed hydrogen coverage of 1/24 ML; (B) TPR of a) Pd/CNF-H and b) Pd@C/CNF-TCH; (C) Valence-band (VB) XPS analysis for a) Pd/CNF-H and b) Pd@C/CNF-TCH; (D) D-projected density of d states of the Pd atoms in clean and C-modified Pd (111) surfaces. 
High-resolution valence-band (VB) XPS analysis was performed to determine the d-band electron structures which is relative to the density of states (DOS). This detail is valuable as it is directly associated with the strength of interaction between the active sites and gaseous molecules ${ }^{44}$. According to the d-band center theory, the adsorption of a molecule on the metal surface leads to hybridization between the metal d-band and an induced state by the guest molecule which contributes to a fully filled bonding DOS and a partially filled anti-bonding DOS states ${ }^{45}$. The filling degree of the anti-bonding states affected by the position of the d-band center relative to the Fermi level $\mathrm{E}_{\mathrm{f}}$ can determine the adsorption strength. Pd@C/CNF-TCH shows a relative shift of the d-band center away from $E_{f}$ (Figure 5C) compared with Pd/CNF-H, leading to a downward shift of the anti-bonding DOS states and thus a weaker interaction with adsorbates. This is due to the fact that there are more electrons available for filling the anti-bonding states, that is, a decreased d-band vacancy for Pd@C/CNF-TCH, which facilitates product desorption. The phenomenon is in agreement with the shift of d-projected density of states (PDOS) to lower energy level of Pd (111)-C, as shown in Figure 5D.

Furthermore, we performed DFT calculations for low-coordinated Pd-carbide based on a slab type model deduced from experimental measurements. Since the surface hydrocarbon species is unstable in the calculated structure, $\mathrm{C}$ atoms were only placed in the subsurface layer of $\mathrm{Pd}(111)$, and thus the amount of $\mathrm{C}$ in the DFT model is lower than that observed experimentally. The Pd:C ratio used for DFT calculation is equal to about 6 at. $\% \mathrm{C}$, which is in agreement with that reported for a $5 \% \mathrm{Pd} / \mathrm{C}$ catalyst, corresponding to a lattice expansion of $1.2 \% .^{41}$ This expansion is also in accordance with the change of optimized lattice parameters before $(3.957 \AA)$ and after carbon insertion into Pd lattice (3.997 $\AA$ ). Therefore, the ratio set is considered to be reasonable. The resulting full potential energy profile for hydrogenation on the Pd-carbide slab is shown in Figure 6. Acetylene adsorbs on two neighboring Pd atoms that are geometrically adjacent to the location of carbon atoms with an adsorption 
energy of $-1.63 \mathrm{eV}$ in the parallel-bridge form. Then, dissociated hydrogen atoms activate and add to the $\mathrm{C} \equiv \mathrm{C}$ bond via in Horiuti-Polanyi type mechanism to form $\mathrm{C}_{2} \mathrm{H}_{4}$ through an ethylene-like $\mathrm{C}_{2} \mathrm{H}_{3} \mathrm{Pd}$ intermediate. The energy barriers of these two steps were calculated as $0.78 \mathrm{eV}$ (TS1) and $0.65 \mathrm{eV}$ (TS2), implying excellent activity of carbide compared with that of high-coordinated Pd sites (see later). The generated $\mathrm{C}_{2} \mathrm{H}_{4}$ molecule has an adsorption energy of $-0.68 \mathrm{eV}$ and remains coordinated on two adjacent $\mathrm{Pd}$ atoms. For further hydrogenation of $\mathrm{C}_{2} \mathrm{H}_{4}$ to $\mathrm{C}_{2} \mathrm{H}_{6}$, the larger and presumably prohibitive barrier of $0.89 \mathrm{eV}$ (TS3) must be overcome meaning that over-hydrogenation of $\mathrm{C}_{2} \mathrm{H}_{4}$ is suppressed ${ }^{46}$. Furthermore, we also investigated the reaction process on the high-coordinated $\mathrm{Pd}$ (111) surface (i.e., equivalent to $\mathrm{Pd} / \mathrm{CNF}-\mathrm{H}$ ). In this case, $\mathrm{C}_{2} \mathrm{H}_{2}$ adsorbs on a 3-fold hollow site with the adsorption energy of $-1.96 \mathrm{eV}$, whereas the kinetic barriers of the first two hydrogenation steps are $0.89 \mathrm{eV}$ (TS1) and $0.92 \mathrm{eV}(\mathrm{TS} 2)$. The difference in transition energy barrier over these two catalysts allows for comment on how fast the elementary step may proceed at $523 \mathrm{~K}$. For the $\mathrm{C}_{2} \mathrm{H}_{2} *+\mathrm{H}^{*}$ step, the energy barriers of $\mathrm{Pd} @ \mathrm{C} / \mathrm{CNF}-\mathrm{TCH}$ and $\mathrm{Pd} / \mathrm{CNF}-\mathrm{H}$ are 0.78 and $0.89 \mathrm{eV}$, respectively. This difference would equate to a reaction rate 11 fold higher for $\mathrm{Pd} @ \mathrm{C} / \mathrm{CNF}-\mathrm{TCH}$. Moreover, the adsorption energy of $\mathrm{C}_{2} \mathrm{H}_{4}$ on $\mathrm{Pd}$ surface is $0.86 \mathrm{eV}$, while the over-hydrogenation barrier is $0.98 \mathrm{eV}$. This barrier for TS3 of Pd (111) is higher than that of Pd@C/CNF-TCH $(0.89 \mathrm{eV})$, giving the latter gives faster reaction of $\mathrm{C}_{2} \mathrm{H}_{4} *$ with $\mathrm{H}^{*}$. However notably, the desorption energy of $\mathrm{Pd} @ \mathrm{C}$ is much lower than the over-hydrogenation barrier of $\mathrm{C}_{2} \mathrm{H}_{4}$, and the difference $\left(\Delta \mathrm{E}_{\mathrm{a}}\right)$ is higher than that of Pd catalyst (Figure S10 and Table S4) ${ }^{47}$; in other words, desorption of ethylene from Pd-carbide is more favourable than for $\mathrm{Pd}$ (111). The calculated adsorption energies from DFT agree well with VB-XPS analysis. Additionally, according to the analysis of DFT calculations, the hydrogenation of $\mathrm{C}_{2} \mathrm{H}_{2} *$ intermediate is regarded as the rate determining step in this system due to this being the step with the maximum energy change. To summarize, treatment in a reaction mixture including $\mathrm{C}_{2} \mathrm{H}_{2} / \mathrm{C}_{2} \mathrm{H}_{4} / \mathrm{H}_{2}$, forms a permeable disordered carbon overlayer with carbon atoms simultaneously inserting into $\mathrm{Pd}$ subsurface as 
temperature in increased to form low-coordinated Pd- $\mathrm{C}_{\text {sub }} @ \mathrm{C}_{\text {layer }}$ sites, which hinder Pd-hydride and weaken ethylene adsorption before over-hydrogenation. Thus, the catalyst exhibits both preferable activity and ethylene selectivity.

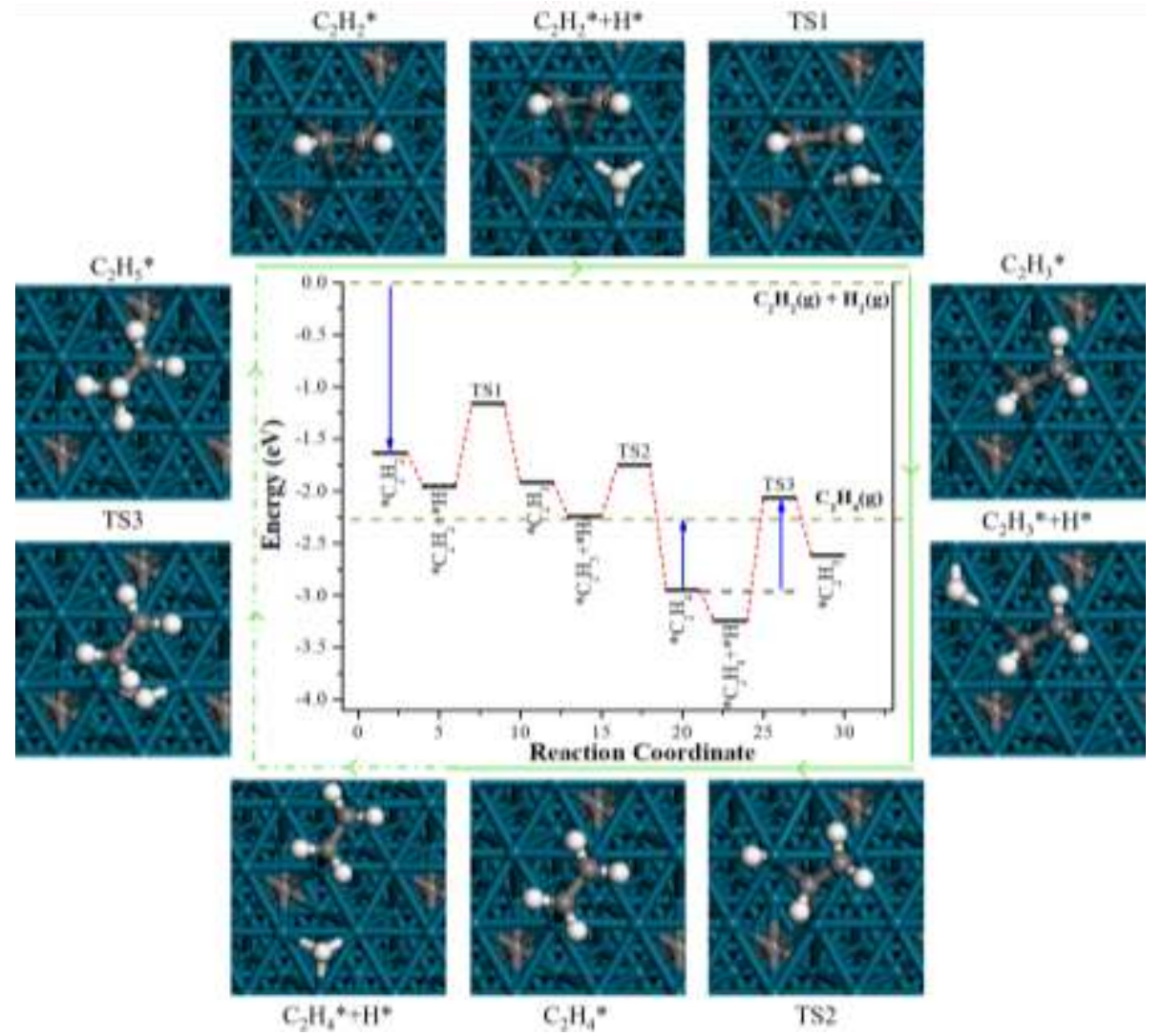

Figure 6. Step-by-step hydrogenation mechanism of acetylene to ethylene over Pd@C/CNF-TCH sample calculated by DFT. The green arrows point out the reaction direction, in which solid line stands for main reaction and dotted line stands for side reaction. The first blue arrows shows the adsorption of $\mathrm{C}_{2} \mathrm{H}_{2}$ (g) to form $\mathrm{C}_{2} \mathrm{H}_{2}{ }^{*}$, while the second and third arrows highlight the desorption of $\mathrm{C}_{2} \mathrm{H}_{4} *$ to form $\mathrm{C}_{2} \mathrm{H}_{4}(\mathrm{~g})$ and hydrogenation to transition state, respectively.

\section{The function of different carbon species on catalytic performance}

From the previous sections, the role of $\mathrm{Pd}-\mathrm{C}_{\text {sub }} @ \mathrm{C}_{\text {layer }}$ sites has been elucidated in Pd@C/CNF-TCH relative to monometallic Pd catalysts; however notably, although $\mathrm{PdC}_{\mathrm{x}}$ exists in the $\mathrm{C}_{2} \mathrm{H}_{2} / \mathrm{C}_{2} \mathrm{H}_{4}$-induced $\mathrm{Pd}$ sample (to a lesser extent than $\mathrm{Pd} @ \mathrm{C} / \mathrm{CNF}-\mathrm{TCH})$, the catalytic performance is not promoted but decreases, suggesting there are other factors that play a decisive role on the catalytic performance in this Pd@C/CNF-TC system. As a result, the role of surface carbon 
species requires further clarify. Fourier Transform Infrared spectroscopy (FTIR), Raman, Thermogravimetry Mass Spectrometry (TGA-MS) and Temperature Programmed Desorption (TPD) techniques were used to investigate the nature and stability of these species. As illustrated in Figure S11, all samples display bands at 1580 and $1640 \mathrm{~cm}^{-1}$ assigned $\mathrm{C}-\mathrm{C}$ stretching and vibrations of a polyaromatic $\mathrm{C}=\mathrm{C}$ bond (likely associated with the CNF support) ${ }^{48}$. The peak at $3440 \mathrm{~cm}^{-1}$ is an experimental artefact caused by $\mathrm{H}_{2} \mathrm{O}$ adsorbed in $\mathrm{KBr}$. After treatment, Pd@C/CNF-TCH (Figure S11-b) shows absorption bands in the range of 2900-3050 $\mathrm{cm}^{-1}$ which are attributed to a $\mathrm{C}-\mathrm{H}$ alkene vibration since a small shoulder can be seen at $3012 \mathrm{~cm}^{-1}$ (due to the $=\mathrm{C}-\mathrm{H}$ stretch). The presence of these vibrations would indicate that some residual alkenes exist on the catalyst surface $\left(\mathrm{C}_{2} \mathrm{H}_{\mathrm{x}}\right)$. In terms of the coupling/fracture of $\mathrm{C}_{2} \mathrm{H}_{2}$ to generate $\mathrm{C}_{4} \mathrm{H}_{4}$ or carbon intermediates, the formation energy barriers are calculated to be 0.97 and $1.63 \mathrm{eV}$, respectively. This means that neither process is more favourable than direct hydrogenation of $\mathrm{C}_{2} \mathrm{H}_{2}$ to $\mathrm{C}_{2} \mathrm{H}_{4}$ on the Pd surface, albeit the difference in the barriers are small so $\mathrm{C}_{2} \mathrm{H}_{\mathrm{x}}$ species laydown is expected (Table S5). The spectra of Pd@C/CNF-TC-1 after $\mathrm{C}_{2} \mathrm{H}_{2} / \mathrm{C}_{2} \mathrm{H}_{4}$ treatment in the absence of hydrogen (i.e., the sample with an equivalent carbon layer thickness of ca $2 \mathrm{~nm}$ ) exhibits bands at $2800-2900 \mathrm{~cm}^{-1}$ and intense contributions at 1000-1400 $\mathrm{cm}^{-1}$. These signals are attributed to $\mathrm{C}-\mathrm{H}$ stretching vibration of $-\mathrm{CH}_{2}$ or $-\mathrm{CH}_{3}$, and various aromatic $\mathrm{CH}$ out-of-plane bending modes, indicating the formation of a different type of surface carbon species. Based on FTIR measurements it is thought that the carbon species in this sample is more graphitic in nature.

This interpretation is further supported by re-examining the $\mathrm{C}$ 1s EELS spectra. The EELS spectra of the support (Figure 2 spot 3 and Figure S7 spot 9) display two peaks at 284 and $291 \mathrm{eV}$ originating from electron excitation from the 1s core level to $\pi^{*}$ anti-bonding and $\sigma^{*}$ anti-bonding orbitals of $\mathrm{C}=\mathrm{C}$ bond (in the ring), respectively ${ }^{49}$. These features are typical for graphite-like materials such as CNF. Equivalent spectra were collected for carbon coated Pd particles of Pd@C/CNF-TC (-1) samples (Figure 2, spot 6 and Figure S7, spot 10) indicating that the carbon on this sample is similar to 
the support in nature with good crystallinity. Interestingly, the spectra associated with carbon on Pd@C/CNF-TCH (Figure 2, spot 4 and Figure S7, spot 8) exhibit a weak $\pi^{*}$ peak at $284 \mathrm{eV}$ and a broad peak spread over a large energy range (290-310 eV), meaning the carbon here is less crystalline and more amorphous. Equivalent results are also observed by Raman (Figure S12).

In analysis of catalyst deactivation in the selective hydrogenation of acetylene, oligomeric species have been shown to form carbon deposits on the surface which can create steric hindrance and inhibit accessibility to active sites. TGA and differential thermal analysis (DTA) was conducted (see Figure S13) and shows weight loss for $\mathrm{Pd} @ \mathrm{C} / \mathrm{CNF}-\mathrm{TCH}$ centered at ca. $523 \mathrm{~K}$ which corresponds to the removal of carbonaceous species which can be easily burnt off $^{21}$. This carbon considered as cracked or permeable based on the test of acid dissolution and must allow access to the $\mathrm{Pd}$ active sites since activity remains high. However, in the case of Pd@C/CNF-TC-1 sample (see Figure S14), only a small mass loss occurs at $523 \mathrm{~K}$ with the majority of carbon combusted at $653 \mathrm{~K}$. This latter peak is assigned to the precursor of graphitic carbon with the structure of an oligomeric hydrocarbon $\left(\mathrm{C}_{\mathrm{x}} \mathrm{H}_{\mathrm{y}}\right)$ 21. In this case, the encapsulated and impermeable carbon overlayers block the Pd active sites. Indeed, in the $\mathrm{H}_{2}$-TPD profiles (Figure S15), the intensity of the peak above $373 \mathrm{~K}$ (ascribed to desorption of chemisorbed hydrogen) is far stronger for $\mathrm{Pd} @ \mathrm{C} / \mathrm{CNF}-\mathrm{TCH}$ than for Pd@C/CNF-TC-1. This gives insight to how different pre-treatments alter carbon layer permeability, and thus modify the accessibility of reactants to active sites.

\section{Discussion}

The treatment of Pd/CNF-H sample with $\mathrm{C}_{2} \mathrm{H}_{2} / \mathrm{C}_{2} \mathrm{H}_{4} / \mathrm{H}_{2}$ leads to an adsorbate induced restructuring which yields $\mathrm{Pd} @ \mathrm{C} / \mathrm{CNF}-\mathrm{TCH}$ sample with an amorphous carbon overlayer (corroborated by STEM, EELS, FTIR and Raman). This layer appears to create a core-shell type structure and is permeable meaning $\mathrm{Pd}$ is still accessible to reactants. Although it is difficult to know the exact nature of the carbon 
layer it is hypothesized to be $\mathrm{C}_{2} \mathrm{H}_{\mathrm{x}}$ intermediates since it can be relatively easily removed in an oxidative environment (TG-DTA-MS). At more elevated temperature (423 K and above) some carbon penetrates in the Pd particles to generate a subsurface Pd-carbide (inferred from XRD, XPS and XAS and the high valence Pd observed by EELS). The formation of the carbide phase is considered as an irreversibly process and hinders Pd-hydride formation. The combined effect of Pd-carbide and the amorphous carbon overlayer to form the more reactive $\mathrm{Pd}-\mathrm{C}_{\text {sub }} @ \mathrm{C}_{\text {layer }}$ sites result in enhanced ethylene selectivity by $20 \%$ and good stability. The transformation of active sites during the reaction process also impacts on the electronic properties of $\mathrm{Pd}$. The downshift in the d-band center away from Fermi level $\left(\mathrm{E}_{\mathrm{f}}\right)$ weakens the $\mathrm{C}_{2} \mathrm{H}_{4}-\mathrm{Pd}$ bond strength and hence facilitates $\mathrm{C}_{2} \mathrm{H}_{4}$ desorption before over-hydrogenation. This interpretation is also in agreement with DFT calculations performed on a Pd-carbide model slab. In contrast, a pre-treatment in the absence of $\mathrm{H}_{2}$ generates an impermeable and crystalline overlayer on metal particles which hinders the reactant access to the active site and has a negative effect on the catalytic reactivity of $\mathrm{Pd}$ catalyst. This work gives insight into the structural transformations which taken place in Pd catalysts during the selective hydrogenation of acetylene to construct the low coordinated $\mathrm{Pd}-\mathrm{C}_{\text {sub }} @ \mathrm{C}_{\text {layer }}$ sites. The results indicate that both the classic $(\mathrm{C}$ overlayer) and contemporary (hydride/carbide) interpretation of factors which influence catalytic performance can simultaneously play a role. The controlled use of adsorbate induced structural changes offers an alternative mechanism by which catalytic performance can be changed.

Except for $\mathrm{H}_{2}-\mathrm{C}_{2} \mathrm{H}_{2}-\mathrm{C}_{2} \mathrm{H}_{4}$, the permeable carbon layer also formed from $\mathrm{H}_{2}-\mathrm{C}_{2} \mathrm{H}_{2}$ mixtures but not from $\mathrm{H}_{2}-\mathrm{C}_{2} \mathrm{H}_{4}$ in the absence of acetylene since the hydrogenation of $\mathrm{C}_{2} \mathrm{H}_{4}$ molecules need to be suppressed in the reaction of selective hydrogenation of $\mathrm{C}_{2} \mathrm{H}_{2}$ to $\mathrm{C}_{2} \mathrm{H}_{4}$. Also, based on existing reports ${ }^{19,} 23-25$, 29, we believe that in situ adsorbate induction method can be extended to the other generally adopted active metal such as Ni, Co Rh, Ru, Pt, PtGa, NiZn, PdGa as the ideal candidates, which locally modifies the reactivity of the underlying metal nanoparticle surface. This 
further research and discussion on the properties of carbon layer derived by different treatment gases and the extension of this methodology to other metals will be performed in the future work.

\section{Conclusion}

In summary, it has been confirmed that $\mathrm{C}_{2} \mathrm{H}_{2} / \mathrm{C}_{2} \mathrm{H}_{4} / \mathrm{H}_{2}$ treated $\mathrm{Pd} / \mathrm{CNF}$ catalysts can drive the formation of a permeable carbon overlayer on Pd and simultaneously induce C diffusion into the Pd lattice to form Pd-carbide phase. The permeable carbon overlayer is stable under operational conditions and enable the reactants access to the active $\mathrm{Pd}-\mathrm{C}_{\text {sub }} @ \mathrm{C}_{\text {layer }}$ sites. The diffusion of $\mathrm{C}$ atoms in to the subsurface (i.e., $\mathrm{C}$ acts as a structural modifier) inhibits hydride formation and facilitates to the desorption of ethylene (confirmed by TPR, XPS, XAS and DFT calculation). The combined structural changes enhance the selectivity and stability of Pd-based catalysts for the selective hydrogenation of acetylene even at high conversion. This improves our understanding of Pd catalysis and opens up a novel route to tune and control the reactivity of supported $\mathrm{Pd}$ catalysts, providing the promising application prospect in industry.

\section{Experimental}

Catalytic testing. Catalytic performance was evaluated in a fixed-bed microreactor at 1 bar. $20 \mathrm{mg}$ of catalyst was diluted with silicon carbide (Aldrich, 200-450 mesh) was placed in the reactor. The inlet gas stream was comprised of $0.6 \%$ acetylene $/ 5.4 \%$ ethylene and $\mathrm{H}_{2}$ diluted by nitrogen. The desired $\mathrm{H}_{2}: \mathrm{C}_{2} \mathrm{H}_{2}$ ratio was 2 and the total flow rate equated to a gas hourly space velocity of $240,000 \mathrm{~h}^{-1}$. Propane was used as an internal standard for the gas chromatography (GC). $5 \mathrm{~h}$ time on stream was permitted for tests where temperature $(323-523 \mathrm{~K})$ was varied. To test catalyst stability additional tests were performed for a continuous $24 \mathrm{~h}$ period at a constant temperature of $523 \mathrm{~K}$. Details for product analysis can be found in the supporting information. 
Characterisation. Cs-corrected STEM images were obtained on a JEOL ARM200F microscope equipped with a probe forming spherical-aberration corrector and a high-angle annular dark-field detector (HAADF), which allows Z-contrast imaging. Electron Energy Loss Spectroscopy (EELS) was employed to probe the chemical nature of the carbon overlayer. The data was analyzed by using Multiple Linear Least Square (MLLS) Fitting within Digital Micrograph Software. In situ XRD patterns were collected using a PANalytical X́ Pert PRO with $\mathrm{Cu}-\mathrm{K} \alpha$ radiation $(\lambda=1.5418 \AA$ A). The diffraction patterns were recorded with an angular step size of $0.05^{\circ}$. The samples were heated stepwise in an Anton Paar XRK 900 reaction chamber from room temperature to $373,423,473$ and $523 \mathrm{~K}$ with a heating rate of $10 \mathrm{~K} \mathrm{~min}^{-1}$. Heating was conducted in a gas mixture which replicated the reaction sequence. Pd edge X-ray absorption spectra (XAS) were measured at the B18 beamline at the Diamond Light Source (Harwell, UK). Pd K-edge XAFS measurements were performed using a QEX AFS set-up with a fast scanning Si (311) double crystal monochromator. The spectra were collected concurrently with the appropriate foil placed between ion detectors $I_{t}$ and $\mathrm{I}_{\text {ref. Data }}$ processing and analysis were analyzed using the IFEFFIT19 package (i.e., Athena and Artemis). The amplitude reduction factor (S02) was chosen as 0.85 . For more experimental details, see Supporting Information.

DFT Calculations. Density functional theory (DFT) calculations were carried out using the Vienna Ab-initio Simulation Package (VASP). Our slab model of Pd (111) surfaces contains a $p(2 \times 2)$ supercells with a total of four atomic layers where the top three atomic layers were relaxed, and the bottom layer was fixed during optimization. The crystal surface modeling of Pd carbide was based on the model of Pd (111), in which $\mathrm{C}$ atoms were evenly placed in the subsurface layer (namely between the third and fourth layers of $\mathrm{Pd}$ atoms) with the ratio of $\mathrm{Pd}$ : $\mathrm{C}=16: 1$. The obtained model was optimized to a stable state. Further calculation details are shown in the supplementary information. 
Supporting Information. Supplementary information is available free of charge on the ACS Publications website.

Long-time on stream test of acetylene conversion and ethylene selectivity at different reaction temperatures, Koros-Nowak test, STEM images and EEL spectra of catalysts, details of DFT calculation of Pd and Pd-C surfaces, further structural characterizations and catalytic performance (PDF).

\section{AUTHOR INFORMATION}

\section{Corresponding Author}

*E-mail address: a.mccue@abdn.ac.uk (A. J. McCue); fengjt@mail.buct.edu.cn (Junting Feng); lidq@mail.buct.edu.cn (Dianqing Li)

Address: Box 98, 15 Bei San Huan East Road, Beijing 100029, China

Tel: +861064436992 Fax: +861064436992

\section{ORCID}
A. J. McCue: 0000-0002-4404-6102
Junting Feng: 0000-0002-6211-9651
Dianqing Li: 0000-0001-6761-8946

\section{Notes}

The authors declare no competing financial interest.

\section{Author contributions}

Y. L. and A. M. conceived and designed the experiment. Y. L. and F. F. synthesized the experimental samples and carried out most of the characterization, as well as the catalytic reactions. B. F. conducted part of experiments and structural analysis. W. J. conducted XAFS experiments and data analysis. D. R. carried out the DFT calculations. Y. L., A. M., J. F. and D. L. discussed the results and wrote the manuscript.

\section{ACKNOWLEDGMENT}

This work was financially supported by National Natural Science Foundation of China (21908002), project funded by China Postdoctoral Science Foundation 
(2019M660416, 2020T130045) and the Fundamental Research Funds for the Central Universities (buctrc201921, JD2004, XK1802-6). We would like to thank the UK catalysis Hub for help collecting the XAS.

\section{REFERENCES}

(1) Borodziński, A.; Bond, G. C. Selective Hydrogenation of Ethyne in Ethene-Rich Streams on Palladium Catalysts. Part 1-Effect of Changes to the Catalyst during Reaction. Catal. Rev. 2016, $48,91-144$.

(2) Nikolaev, S. A.; Zanaveskin, I. L. N.; Smirnov, V. V.; Averyanov, V. A.; Zanaveskin, K. I. Catalytic Hydrogenation of Alkyne and Alkadiene Impurities in Alkenes: Practical and Theoretical Aspects. Chem. Rev. 2009, 78, 231-247.

(3) McCue, A. J.; Anderson, J. A. Recent Advances in Selective Acetylene Hydrogenation Using Palladium Containing Catalysts. Front. Chem. Sci. Eng. 2015, 9, 142-153.

(4) Mei, D. H.; Sheth, P. A.; Neurock, M.; Smith, C. M. First Principles-based Kinetic Monte Carlo Simulation of the Selective Hydrogenation of Acetylene over Pd (111), J. Catal. 2006, 242, $1-15$.

(5) Borodziński, A.; Bond, G. C. Selective Hydrogenation of Ethyne in Ethene-Rich Streams on Palladium Catalysts, Part 2: Steady-State Kinetics and Effects of Palladium Particle Size, Carbon Monoxide, and Promoters. Catal. Rev. 2008, 50, 379-469.

(6) Teschner, D.; Borsodi, J.; Wootsch, A.; Révay, Z.; Hävecker, M.; Knop-Gericke, A.; Jackson, S. D.; Schlögl, R. The Roles of Subsurface Carbon and Hydrogen in Palladium-Catalyzed Alkyne Hydrogenation. Science 2008, 320, 86-89.

(7) Han, Y. X.; Peng, D.; Xu, Z. Y.; Wan, H. Q.; Zheng, S. R.; Zhu, D. Q. TiO 2 Supported Pd@Ag as Highly Selective Catalysts for Hydrogenation of Acetylene in Excess Ethylene. Chem. Commun. 2013, 49, 8350-8532.

(8) Huang, F.; Deng, Y. C.; Chen, Y. L.; Cai, X. B.; Peng, M.; Jia, Z. M.; Xie, J. L.; Xiao, D. Q.; Wen, X. D.; Wang, N.; Jiang, Z.; Liu, H.Y.; Ma, D. Anchoring $\mathrm{Cu}_{1}$ Species over Nanodiamond-Graphene for Semi-Hydrogenation of Acetylene. Nat. Commun. 2019, 10, 4431.

(9) Zhou, S. Q.; Shang, L.; Zhao, Y. X.; Shi, R.; Waterhouse, G. I. N.; Huang, Y.C.; Zheng, L. R.; Zhang, T. R. Pd Single-Atom Catalysts on Nitrogen-Doped Graphene for the Highly Selective Photothermal Hydrogenation of Acetylene to Ethylene. Adv. Mater. 2019, 31, 1900509.

(10) Yang, L. N.; Guo, Y. S.; Long, J.; Xia, L.X.; Li, D.; Xiao, J. P.; Liu, H. Y. PdZn Alloy Nanoparticles Encapsulated within A Few Layers of Graphene for Efficient Semi-Hydrogenation 
of Acetylene. Chem. Commun. 2019, 55, 14693-14696.

(11) Liu Y. N.; McCue, A. J.; Yang, P. F.; He, Y. F.; Zheng, L. R.; Cao, X. Z.; Man, Y.; Feng, J. T.; Anderson, J. A.; Li, D. Q. Support Morphology-Dependent Alloying Behaviour and Interfacial Effects of Bimetallic Ni-Cu/CeO ${ }_{2}$ Catalysts. Chem. Sci. 2019, 10, 3556-3566.

(12) Zhou, S. L.; Gao, L. Y.; Wei, F. F.; Lin, S.; Guo, H. On the Mechanism of Alkyne Hydrogenation Catalyzed by Ga-Doped Ceria. J. Catal. 2019, 375, 410-418.

(13) Albani, D.; Shahrokhi, M.; Chen, Z. P.; Mitchell, S.; Hauert, R.; López N.; Pérez-Ramírez, J. Selective Ensembles in Supported Palladium Sulfide Nanoparticles for Alkyne Semi-Hydrogenation. Nat. Commun. 2018, 9, 2634.

(14) Liu, Y. N.; Li, Y. W.; Anderson, J. A.; Feng, J. T.; Guerrero-Ruiz, A.; Rodríguez-Ramos, I.; McCue, A. J.; Li, D. Q. Comparison of $\mathrm{Pd}_{\text {and }} \mathrm{Pd}_{4} \mathrm{~S}$ Based Catalysts for Partial Hydrogenation of External and Internal Butynes. J. Catal. 2020, 383, 51-59.

(15) Liu, Y. N.; McCue, A. J.; Miao, C. L.; Feng, J. T.; Li, D. Q.; Anderson, J. A. Palladium Phosphide Nanoparticles as Highly Selective Catalysts for the Selective Hydrogenation of Acetylene. J. Catal. 2018, 364, 406-414.

(16) Chen, Y. D.; Li, C. M.; Zhou, J. Y.; Zhang, S. T.; Rao, D. M.; He, S.; Wei, M.; Evans, D. G.; Duan, X. Metal Phosphides Derived from Hydrotalcite Precursors toward the Selective Hydrogenation of Phenylacetylene. ACS Catal. 2015, 5, 5756-5765.

(17) Viñes, F.; Loschen, C.; Illas, F.; Neyman, K. M. Edge Sites as a Gate for Subsurface Carbon in Palladium Nanoparticles. J. Catal. 2009, 266, 59-63.

(18) Studt, F.; Abild-Pedersen, F.; Bligaard, T.; Sørensen, R. Z.; Christensen, C. H.; Nørskov, J. K. On the Role of Surface Modifications of Palladium Catalysts in the Selective Hydrogenation of Acetylene. Angew. Chem. Int. Ed. 2008, 120, 9439-9442.

(19) Garcia-Ortiz, A.; Vidal, J.D.; Iborra, S.; Climent, M. J.; Cored, J.; Ruano, D.; Pérez-Dieste, V.; Concepción, P.; Corma, A. Synthesis of a Hybrid $\mathrm{Pd}^{0} / \mathrm{Pd}-$ Carbide/Carbon Catalyst Material with High Selectivity for Hydrogenation Reactions, J. Catal. 2020, 389, 706-713.

(20) Deng, J.; Ren, P.; Deng, D.; Bao, X. H. Enhanced Electron Penetration through an Ultrathin Graphene Layer for Highly Efficient Catalysis of the Hydrogen Evolution Reaction. Angew. Chem. Int. Ed. 2015, 54, 2100-2104.

(21) Azizi, Y.; Petit, C.; Pitcho, V. Formation of Polymer-Grade Ethylene by Selective Hydrogenation of Acetylene over $\mathrm{Au} / \mathrm{CeO}_{2}$ Catalyst. J. Catal. 2008, 256, 338-344.

(22) Jin, Y. M.; Datye, A. K.; Rightor, E.; Gulotty, R.; Waterman, W.; Smith, M.; Holbrook, M.; Maj, J.; Blacksony, J. The Influence of Catalyst Restructuring on the Selective Hydrogenation of Acetylene to Ethylene. J. Catal. 2001, 203, 292-306.

(23) Niu, Y. N.; Huang, X.;Wang, Y. Z.; Xu, M.; Chen, J. N.; Xu, S. L.; Willinger, M-G.; Zhang, W.; Wei, M.; Zhang, B. S. Manipulating Interstitial Carbon Atoms in the Nickel Octahedral Site 
for Highly Efficient Hydrogenation of Alkyne, Nat. Commun. 2020, 11, 3324.

(24) Kim, H.; Robertson, A. W.; Kim, S. O.; Kim, J. M.; Warner, J. H. Resilient High Catalytic Performance of Platinum Nanocatalysts with Porous Graphene Envelope, ACS Nano 2015, 9, 5947-5957.

(25) Kaiser, S. K.; Lin, R.; Krumeich, F.; Safonova, O. V.; Pérez-Ramírez, J. Preserved in a Shell: High-Performance Graphene-Confined Ruthenium Nanoparticles in Acetylene Hydrochlorination, Angew. Chem. Int. Ed. 2019, 58, 12297-12304.

(26) Bachiller-Baeza, B.; Iglesias-Juez, A.; Castillejos-López, E.; Guerrero-Ruiz, A.; Di Michiel, M.; Fernández-García, M.; Rodríguez-Ramos, I. Detecting the Genesis of a High-Performance Carbon-Supported Pd Sulfifide Nanophase and Its Evolution in the Hydrogenation of Butadiene, ACS Catal. 2015, 5, 5235-5241.

(27) Mei, D. H.; Neurock, M.; Smith, C. M. Hydrogenation of Acetylene-Ethylene Mixtures over Pd and Pd-Ag alloys: First-Principles-Based Kinetic Monte-Carlo Simulations. J. Catal. 2009, 268, 181-195.

(28) Liu, Y. N.; Zhao, J.; Feng, J.; He, Y.; Du, Y.; D. Li, Layered Double Hydroxide-Derived $\mathrm{Ni}-\mathrm{Cu}$ Nanoalloy Catalysts for Semi-Hydrogenation of Alkynes: Improvement of Selectivity and Anti-Coking Ability via Alloying of $\mathrm{Ni}$ and Cu. J. Catal. 2018, 359, 251-260.

(29) Matsubu, J. C.; Zhang, S. Y.; DeRita, L.; Marinkovic, N. S.; Chen, J. G.; Graham, G. W.; Pan, X. Q.; Christopher, P. Adsorbate-Mediated Strong Metal-Support Interactions in Oxide-Supported Rh Catalysts. Nat. Chem. 2017, 9, 120-127.

(30) Liu, L. C.; Concepción, P.; Corma, A. Non-Noble Metal Catalysts for Hydrogenation: A Facile Method for Preparing Co Nanoparticles Covered with Thin Layered Carbon. J. Catal. 2019, $340,1-9$.

(31) Baldi, A.; Narayan, T. C.; Koh, A. L.; Dionne, J. A. In situ Detection of Hydrogen-Induced Phase Transitions in Individual Palladium Nanocrystals. Nat. Mater. 2014, 13, 1143-1148.

(32) Sun, K.; Liu, J.; Nag, N. K. Atomic Scale Characterization of Supported Pd-Cu/ $\gamma-\mathrm{Al}_{2} \mathrm{O}_{3}$ Bimetallic Catalysts. J. Phys. Chem. B 2002, 106, 12239-12246.

(33) Okuyama, H.; Siga, W.; Takagi, N.; Nishijima M.; Aruga, T. Path and Mechanism of Hydrogen Absorption at Pd (100). Surf. Sci. 1998, 401, 344-354.

(34) Datsyuk, V.; Kalyva, M.; Papagelis, K. Chemical Oxidation of Multiwalled Carbon Nanotubes. Carbon 2008, 46, 833-840.

(35) Teschner, D.; Vass, E.; Hävecker, M.; Zafeiratos, S.; Schnörch, P.; Sauer, H.; Knop-Gericke, A.; Schlögl, R.; Chamam, M.; Wootsch, A.; Canning, A. S.; Gamman, J. J.; Jackson, S. D.; McGregor, J.; Gladden, L. F. Alkyne Hydrogenation over Pd Catalysts: A New Paradigm. J. Catal. 2006, 242, 26-37.

(36) Crespo-Quesada, M.; Yoon, S.; Jin, M. S.; Prestianni, A.; Cortese, R.; Cárdenas-Lizana, F.; 
Duca, D.; Weidenkaff, A.; Kiwi-Minsker, L. Shape-Dependence of Pd Nanocrystal Carburization during Acetylene Hydrogenation. J. Phys. Chem. C 2015, 119, 1101-1107.

(37) Ziemecki, S. B.; Jones, G. A.; Swartzfager, D. G.; Harlow, R. L. Formation of Interstitial Pd-C Phase by Interaction of Ethylene, Acetylene and Carbon-Monoxide with Palladium. J. Am. Chem. Soc. 1985, 107, 4547-4548.

(38) Tew, M. W.; Janousch, M.; Huthwelker, T.; Van Bokhoven, J. A. The Roles of Carbide and Hydride in Oxide-Supported Palladium Nanoparticles for Alkyne Hydrogenation. J. Catal. 2011, $283,45-54$.

(39) McCauaaey, J. A. In-Situ X-ray Absorption Spectroscopy Studies of Hydride and Carbide Formation in Supported Palladium Catalysts. J. Phys. Chem. 1993, 97, 10372.

(40) Bugaev, A. L.; Gudaa, A. A.; Lazzarini, A.; Lomachenkoa, K. A.; Groppob, E.; Pellegrinic, R.; Piovanod, A.; Emeriche, H.; Soldatova, A. V.; Bugaeva, L. A.; Dmitrieva, V. P.; Bokhovenf, J. A.; Lamberti, C. In Situ Formation of Hydrides and Carbides in Palladium Catalyst: When XANES is Better Than EXAFS and XRD. Catal. Today 2017, 283, 119-126.

(41) Tew, M. W.; Nachtegaal, M.; Janousch, M.; Huthwelker, T.; Van Bokhoven, J. A. The Irreversible Formation of Palladium Carbide during Hydrogenation of 1-Pentyne over Silica-Supported Palladium Nanoparticles: In Situ Pd K and L3 Edge XAS. Phys. Chem. Chem. Phys. 2012, 14, 5761-5768.

(42) Yang, B.; Burch, R.; Hardacre, C.; Hu, P.; Hughes, P. Selective Hydrogenation of Acetylene over Pd-Boron Catalysts: A Density Functional Theory Study. J. Phys. Chem. C 2014, 118, 3664-3671.

(43) Liu, Y.; He, Y.; Zhou, D.; Feng, J.; Li, D. Catalytic Performance of Pd-Promoted Cu Hydrotalcite-Derived Catalysts in Partial Hydrogenation of Acetylene: Effect of $\mathrm{Pd}-\mathrm{Cu}$ Alloy Formation. Catal. Sci. Technol. 2016, 6, 3027-3037.

(44) Kim, D. Y.; Resasco, J.; Yu, Y.; Asiri, A. M.; Yang, P. D. Synergistic Geometric and Electronic Effects for Electrochemical Reduction of Carbon Dioxide using Gold-Copper Bimetallic Nanoparticles. Nat. Commun. 2014, 5, 4948.

(45) Wang, W.; Shang, L.; Chang, G. J.; Waterhouse, G. I. N.; Zhang, T. R. Intrinsic Carbon-Defect-Driven Electrocatalytic Eeduction of Carbon Dioxide. Adv. Mater. 2019, 31, 1808276-1808283.

(46) Feng, Q.; Zhao, S.; Wang, Y.; Dong, J.; Chen, W.; He, D.; Wang, D.; Yang, J.; Zhu, Y.; Zhu, H.; Gu, L.; Li, Z.; Liu, Y.; Yu,R.; Li, J.; Li, Y. Isolated Single-Atom Pd Sites in Intermetallic Nanostructures: High Catalytic Selectivity for Semihydrogenation of Alkynes. J. Am. Chem. Soc. 2017, 139, 7294-7301.

(47) Yang, B.; Burch, R.; Hardacre, C.; Headdock, G.; Hu, P. Origin of the Increase of Activity and Selectivity of Nickel Doped by $\mathrm{Au}, \mathrm{Ag}$, and $\mathrm{Cu}$ for Acetylene Hydrogenation. ACS Catal. 2012, 2, 1027-1032. 
(48) Zhou, J. H.; Sui, Z. J.; Zhu, J. Characterization of Surface Oxygen Complexes on Carbon Nanofibers by TPD, XPS and FT-IR. Carbon 2007, 45, 785-796.

(49) Arrigo, R.; Schuster, M. E.; Xie, Z.; Yi, Y.; Wowsnick, G.; Sun, L. L.; Hermann, K. E.;

Friedrich, M.; Kast. P.; Hävecker, M.; Knop-Gericke, A.; Schlögl, R. Nature of the N-Pd Interaction in Nitrogen-Doped Carbon Nanotube Catalysts, ACS Catal. 2015, 5, 2740-2753. 


\section{Graphic for manuscript}

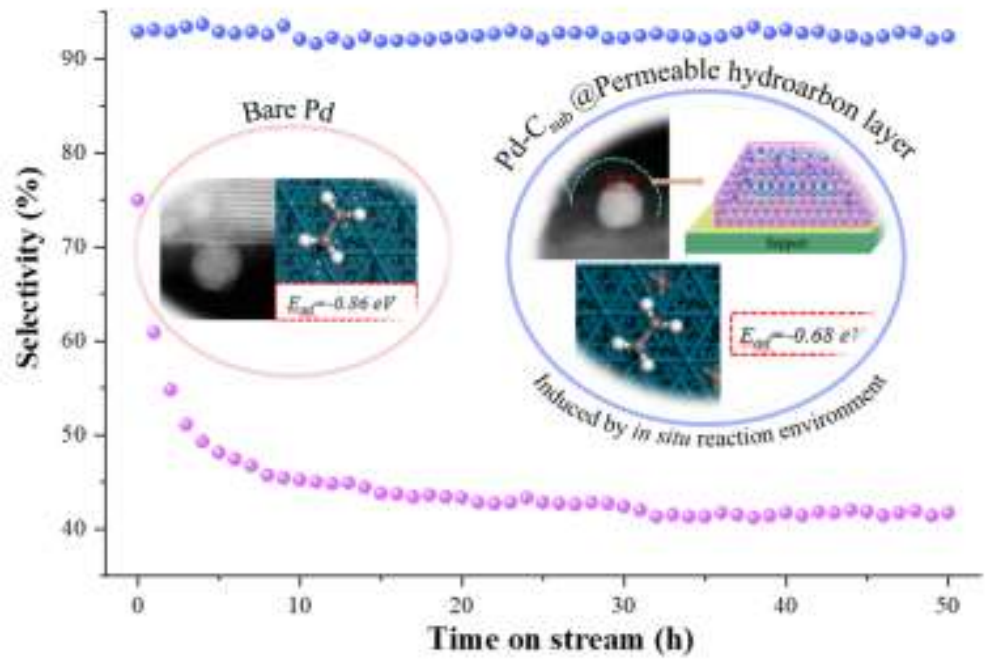

